\title{
Characterization of two new degradation products of atorvastatin calcium formed upon treatment with strong acids
}

\author{
Jürgen Krauß ${ }^{1}$, Monika Klimt ${ }^{1}$, Markus Luber ${ }^{1}$, Peter Mayer ${ }^{2}$ and Franz Bracher ${ }^{* 1}$
}

Full Research Paper

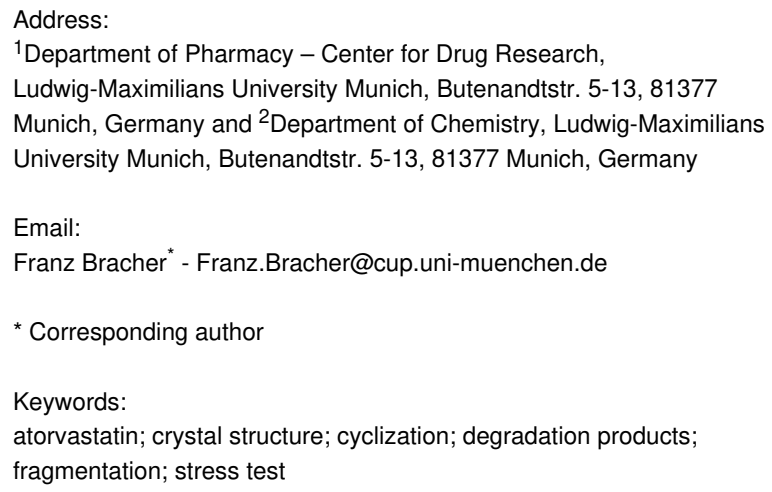

Beilstein J. Org. Chem. 2019, 15, 2085-2091. doi:10.3762/bjoc. 15.206

Received: 27 May 2019

Accepted: 22 August 2019

Published: 02 September 2019

This article is part of the thematic issue "Reactive intermediates carbocations" and is dedicated to the memory of Prof. Dr. Gerhard Rücker, Bonn.

Guest Editor: S. R. Hare

() 2019 Krauß et al.; licensee Beilstein-Institut. License and terms: see end of document.

\begin{abstract}
Atorvastatin calcium (Lipitor ${ }^{\circledR}$, Sortis ${ }^{\circledR}$ ) is a well-established cholesterol synthesis enzyme (CSE) inhibitor commonly used in the therapy of hypercholesterolemia. This drug is known to be sensitive to acid treatment, but only little data has been published on the structures of the degradation products. Here we report the identification of two novel degradation products of atorvastatin, which are formed only under drastic acidic conditions. While treatment with conc. sulfuric acid led to a loss of the carboxanilide residue (accompanied by an expectable lactonization/dehydration process in the side chain), treatment with conc. aqueous hydrochloric acid gave a complex, bridged molecule under $\mathrm{C}-\mathrm{C}$-bond formation of the lactone moiety with the pyrrole, migration of the isopropyl group and loss of the carboxanilide residue. The novel degradation products were characterized by NMR spectroscopy, HRMS data and X-ray crystal structure analysis.
\end{abstract}

\section{Introduction}

Over the past decades, the general trend toward globalization of the supply chains for active pharmaceutical ingredients has created new challenges for the authorities in ensuring the safety and quality of the drug supply [1]. Unprecedented impurities can appear, most likely if limited information is available about details (or alterations) of production processes of drugs. On the one hand, it is impossible to check drug substances routinely for all imaginable impurities, on the other hand it is desirable to identify as much as possible degradation products of drugs resulting from inappropriate exposition to potentially harmful conditions during production, manufacturing and storage. For being able to provide relevant data in a manageable time frame, two kinds of stress tests have found broad application: accelerated storage conditions (higher temperatures, higher 
humidity, ...) typically provide reliable data on the stability of a drug, but are still time-consuming; on the other hand in "forced degradation experiments" the drug is submitted to more drastic conditions (e.g., strong acid or base, strong oxidant, very high temperature), and potential degradation products can be identified in very short time [2,3]. However, forced degradation experiments are highly artificial in nature, and thus one has to keep in mind that these extremely drastic conditions are prone to lead to results that might be out of proportion for daily quality control [3]. Nevertheless, knowledge about the outcome of stress tests under extreme conditions helps to get insight into the overall reactivity of drug substances.

Atorvastatin calcium (1, marketed as the trihydrate in Lipitor ${ }^{\circledR}$, Sortis ${ }^{\circledR}$ ), is a well-established drug for treatment of hypercholesterolemia [4]. This drug is monographed in the leading pharmacopoeias (Ph. Eur., USP), and a couple of impurities are listed there. Most of these impurities result from the synthesis process (stereoisomers, products resulting from impure starting materials or side reactions), and only one of these impurities, lactone $\mathbf{2}$, is most likely a degradation product, resulting from acid-mediated lactonization of the 3,5-dihydroxyheptanoate side chain.

A couple of previous publications deal with stress tests on atorvastatin (and its salts), and an overview has been published by Sirén [5]. Hereby, atorvastatin was found to be sensitive to acidic, oxidative, photochemical and thermal stress. Acidic degradation of atorvastatin was reported to follow first order kinetics, but decomposition products were not characterized in this [6] and several other reports, which only determined the downsizing of the atorvastatin peak in HPLC after treatment with acid [7-10]. The most prominent decomposition product upon acidic treatment, compound $\mathbf{2}$, results from lactonization of the 3,5-dihydroxyheptanoate side chain under moderately acidic conditions (0.1 M HCl) [11-14]. Shah et al. [15] identified six additional decomposition products upon treatment with $0.1 \mathrm{M} \mathrm{HCl}$ at $80{ }^{\circ} \mathrm{C}$ for $24 \mathrm{~h}$, among which the dehydrated lactone 3 was dominating, accompanied by minor amounts of products arising from dehydration of the $\delta$-hydroxy group and some epimers resulting from acid-catalyzed isomerization reactions. In contrast, Vukkum et al. [13] describe, besides lactones $\mathbf{2}$ and $\mathbf{3}$, an $\alpha, \beta$-unsaturated carboxylic acid $\mathbf{4}$. Treatment under more drastic conditions ( $6 \mathrm{M} \mathrm{HCl}$, reflux, $3 \mathrm{~h}$ ) was reported to result mainly in hydrolysis of the anilide moiety to give carboxylic acid 5 [16,17] (Figure 1).

Here we report on the results of our investigations on the decomposition of atorvastatin calcium (1) under strongly acid conditions.

\section{Results and Discussion Stress tests}

Since the lability of atorvastatin towards moderately acidic conditions is well-documented, we aimed at investigating the outcome of incubation with acids under more drastic conditions. Treatment of atorvastatin calcium trihydrate (1) with $2 \mathrm{M}$ aqueous hydrochloric acid at room temperature (Table 1, entry 1) gave, in accordance with previous reports, only hydroxylactone 2 (55\% yield). This outcome was confirmed by comparison with published NMR data $[18,19]$. At elevated temperature (reflux, 4 h; Table 1, entry 2) a mixture of lactone $\mathbf{2}$ and known unsaturated lactone 3 [15] (arising from acid-catalyzed dehydration of 2) was obtained. Under even more drastic acidic conditions (refluxing with $6 \mathrm{M}$ hydrochloric acid for $3 \mathrm{~h}$, with $20 \%$ aqueous $\mathrm{H}_{2} \mathrm{SO}_{4}$ for $2 \mathrm{~h}$, or with $p$-toluenesulfonic acid in toluene for $5 \mathrm{~h}$; Table 1, entries 3-5) unsaturated lactone 3 was formed exclusively and in high to almost quantitative yields (Table 1).

When atorvastatin calcium trihydrate (1) was submitted to extremely strong acidic conditions by refluxing with concentrated $(37 \%)$ aqueous hydrochloric acid (entry 6), a new product 6 was formed in almost quantitative yield. The ${ }^{1} \mathrm{H}$ NMR analysis clearly indicated that the entire carboxanilide partial structure got lost under these conditions. However, no signal was observed which could be attributed to a $\mathrm{C}-\mathrm{H}$ group at the pyrrole ring. The ${ }^{13} \mathrm{C}$ NMR data showed one carbonyl resonance at $170.3 \mathrm{ppm}$, assignable to a lactone moiety. The HMBC experiment showed a cross peak between the proposed lactone carbonyl carbon and a neighboring $\mathrm{CH}-\mathrm{O}$ group, confirming the lactone moiety, and the DEPT spectrum showed a new aliphatic methine resonance at $25.2 \mathrm{ppm}$. By HRESIMS mass data (found: 404.2020 for $\left[\mathrm{M}+\mathrm{H}^{+}\right.$) a molecular formula of $\mathrm{C}_{26} \mathrm{H}_{26} \mathrm{FNO}_{2}$ was confirmed, excluding incorporation of $\mathrm{HCl}$ into this artefact. Finally, X-ray crystallography structure analysis (see Figure 2 and Supporting Information File 1) disclosed the structure of $\mathbf{6}$, bearing a novel, bridged tricyclic 1,5methanopyrrolo[1,2-e][1,5]oxazonin-3-one ring system (Scheme 1).

In contrast, submission of atorvastatin calcium trihydrate (1) to concentrated sulfuric acid for two hours at $60{ }^{\circ} \mathrm{C}$ (Table 1 , entry 7) led to the degradation product 7 in low yield (18\%) (Scheme 1). No further decomposition products could be isolated. Here, lactonization and dehydration steps in the side chain took place as observed before in the other acid treatments, however, under these extremely strong, virtually anhydrous acid conditions, the entire carboxanilide residue was removed to give the $(S)$-configured 4-unsubstituted pyrrole 7, as exemplified by a typical $\mathrm{CH}$ resonance at $6.20 \mathrm{ppm}$ in the ${ }^{1} \mathrm{H}$ NMR spectrum. This structure was further 


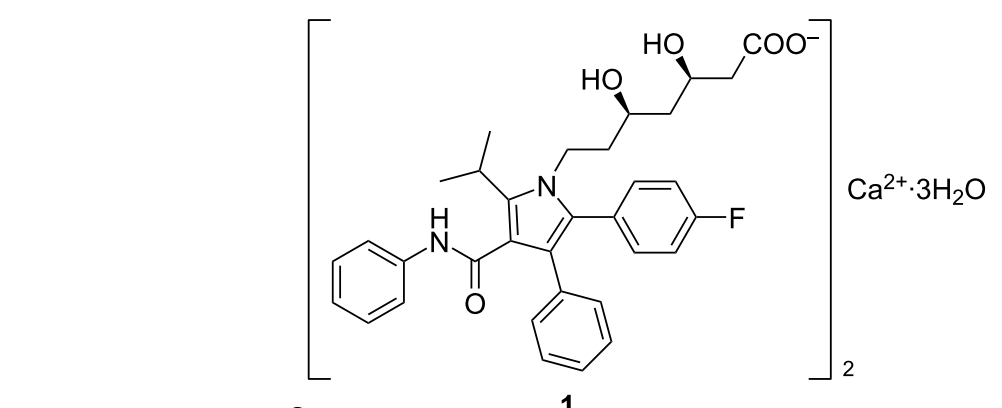

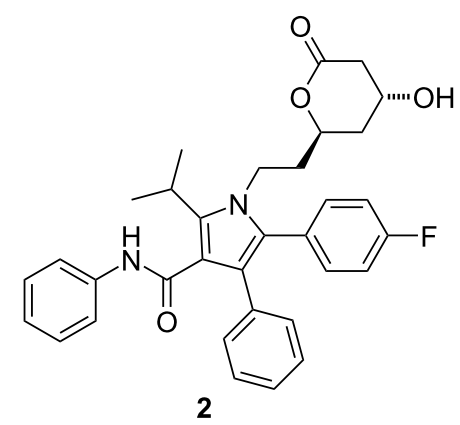
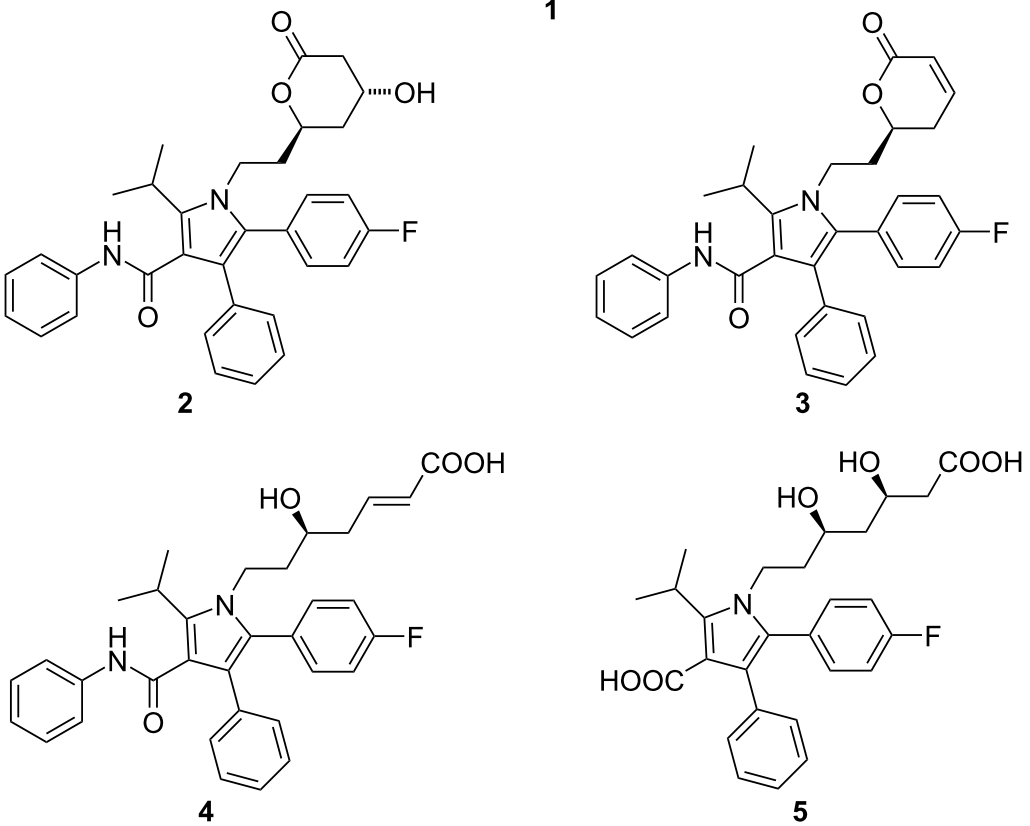

Figure 1: Atorvastatin calcium trihydrate (1) and previously published decomposition products arising from treatment with acids: lactone 2 , dehydrated lactone $3, \alpha, \beta$-unsaturated carboxylic acid $\mathbf{4}$, and carboxylic acid $\mathbf{5}$ (resulting from postulated anilide hydrolysis).

\begin{tabular}{|c|c|c|c|c|c|}
\hline \multirow[t]{2}{*}{ Entry no. } & \multirow[t]{2}{*}{ Acidic conditions } & \multicolumn{4}{|c|}{ Decomposition products (yield) } \\
\hline & & 2 & 3 & 6 & 7 \\
\hline 1 & $2 \mathrm{M} \mathrm{HCl}, 20^{\circ} \mathrm{C}, 2 \mathrm{~h}$ & $55 \%$ & - & - & - \\
\hline 2 & $2 \mathrm{M} \mathrm{HCl}$, reflux, $4 \mathrm{~h}$ & $65 \%$ & $14 \%$ & - & - \\
\hline 3 & $6 \mathrm{M} \mathrm{HCl}$, reflux, $3 \mathrm{~h}$ & - & $70 \%$ & - & - \\
\hline 4 & $20 \% \mathrm{H}_{2} \mathrm{SO}_{4}$, reflux, $2 \mathrm{~h}$ & - & $>98 \%$ & - & - \\
\hline 5 & $p$-toluenesulfonic acid, toluene, reflux, $5 \mathrm{~h}$ & - & $95 \%$ & - & - \\
\hline 6 & $37 \% \mathrm{HCl}$, reflux, $5 \mathrm{~h}$ & - & - & $96 \%$ & - \\
\hline 7 & conc. $\mathrm{H}_{2} \mathrm{SO}_{4}, 60^{\circ} \mathrm{C}, 2 \mathrm{~h}$ & - & - & - & $18 \%$ \\
\hline
\end{tabular}

confirmed by X-ray data (see Figure 2 and Supporting Information File 1).

\section{HPLC method for the detection of the novel impurities}

In order to provide a convenient method for including our new findings into quality control of atorvastatin batches, we worked out an isocratic HPLC protocol, which prettily separates the four artefacts $\mathbf{2}, \mathbf{3}, \mathbf{6}$ and $\mathbf{7}$ from atorvastatin (1). This method uses an RP18 stationary phase (Eurospher 100-C18), isocratic elution with $0.01 \mathrm{M}$ ammonium acetate buffer $(\mathrm{pH} 4)$-acetonitrile 54:46 (v/v) at a flow rate of $1 \mathrm{~mL} / \mathrm{min}$ at $40{ }^{\circ} \mathrm{C}$, with UV detection at $246 \mathrm{~nm}$ (Figure 3). 
$\stackrel{\text { conc. } \mathrm{HCl}}{\longrightarrow}$

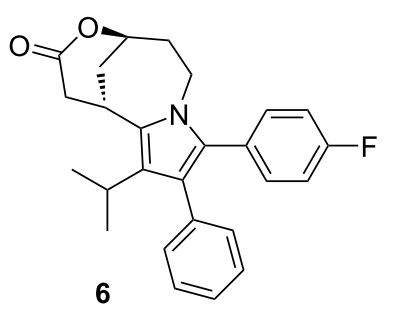

1

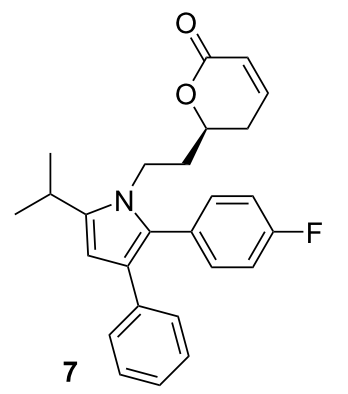

Scheme 1: Formation of novel artefacts 6 and 7 under extremely strong acidic conditions.

\section{Discussion}

In this investigation we first confirmed some pathways of decomposition of atorvastatin under acidic conditions. With dilute mineral acids at room temperature, atorvastatin is conveniently converted into the lactone 2 under retention at the $\mathrm{C} 5-\mathrm{O}$ bond of the aliphatic chain $[13,20]$, whereas treatment under more drastic conditions (e.g., $6 \mathrm{M} \mathrm{HCl}$ or heating) causes expectable subsequent dehydration to give the unsaturated lactone $\mathbf{3}$ $[13,15]$. In contrast to previous reports $[16,17]$ we could not find any indication for a cleavage of the carboxanilide partial structure to give free pyrrolecarboxylic acid $\mathbf{5}$ under treatment with $6 \mathrm{M} \mathrm{HCl}$ under reflux.

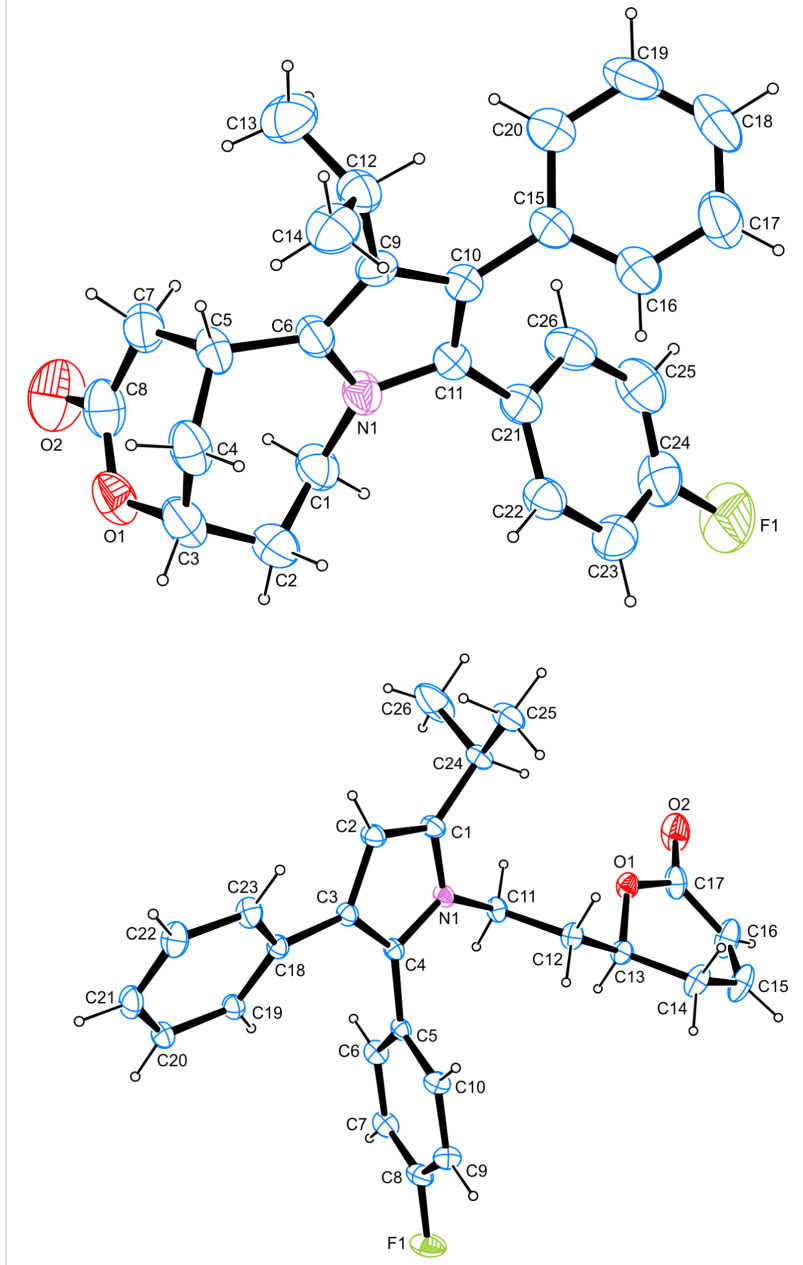

Figure 2: Top: Molecular structure of artefact 6 . Shown here is the molecular structure of one of three independent molecules in $\mathbf{6}$ drawn at the $50 \%$ ellipsoid probability level. Bottom: Molecular structure of artefact 7 (drawn at the $50 \%$ ellipsoid probability level).

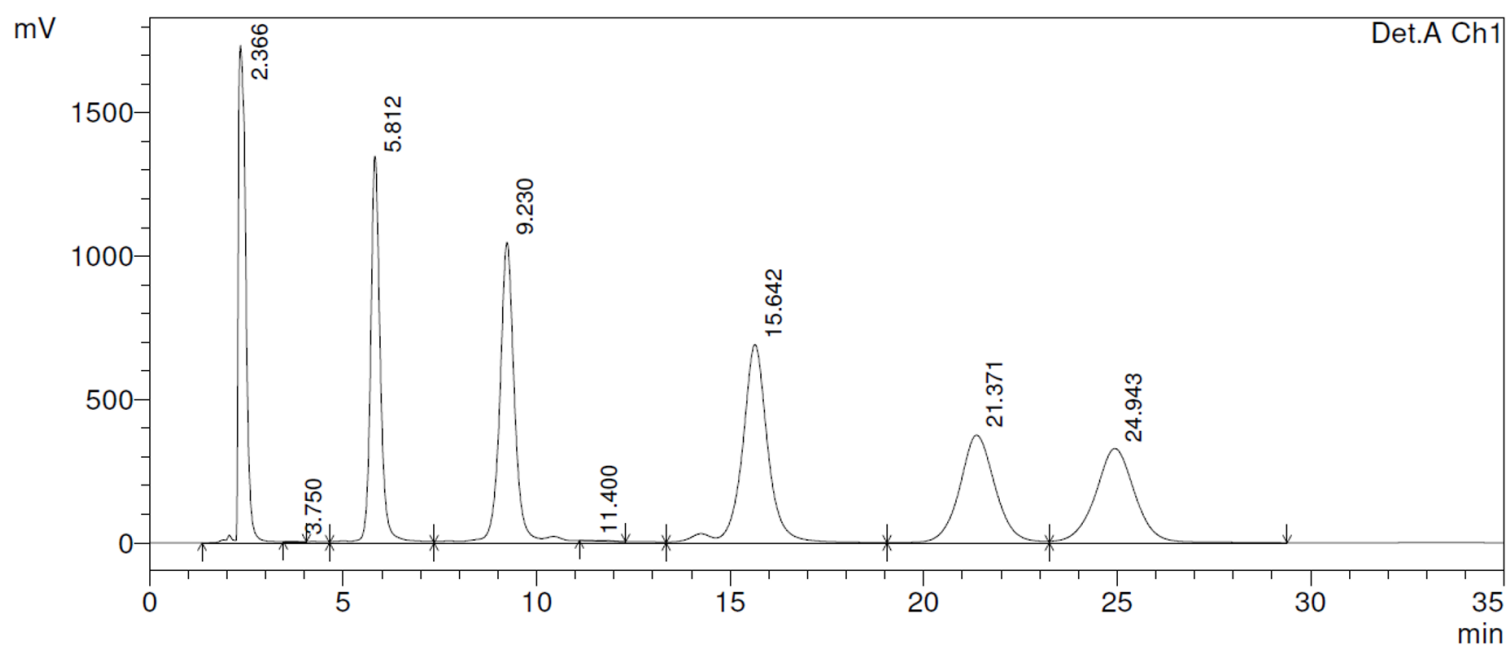

Figure 3: Separation of atorvastatin (1; retention time: $5.8 \mathrm{~min}$ ) from the four decomposition products 2 (retention time: $9.2 \mathrm{~min}$ ), 3 (retention time: $15.6 \mathrm{~min}$ ), 6 (retention time: $21.4 \mathrm{~min}$ ) and 7 (retention time: $24.9 \mathrm{~min}$ ). Chromatogram obtained with a solution containing $10 \mathrm{mg}$ each in $5.0 \mathrm{~mL}$ DMF (retention time $2.3 \mathrm{~min}$ ), diluted 1:5 with the eluent buffer before injection. 
However, upon treatment with concentrated sulfuric acid, lactonization/dehydration is accompanied by complete loss of the carboxanilide residue to give pyrrole 7. Complete one-step removal of carboxamide residues from aromatic rings has been observed before in investigations of fragmentations of protonated species in mass spectrometry $[21,22]$. For benzanilides Tu [21] proposed a mechanism involving protonation of the amide oxygen, followed by 1,3 proton shift to the ring carbon next to the amide carbonyl group, followed by elimination of protonated phenyl isocyanate under re-aromatization. For the pyrrole derived substrate investigated here, even direct protonation at C-3 of the pyrrole by strong acid is most likely, due to the significant basicity of pyrroles. Delocalization of the positive charge (A $\leftrightarrow \mathbf{A}^{\prime}$ ) as shown in Scheme 2 will support the initial ring protonation step. The X-ray analysis of compound 7 revealed that the asymmetric center in the lactone ring is $(S)$ configured, indicating that once again the lactonization step took place with retention at the remaining stereocenter (the shift from $(R)$ to $(S)$ configuration is only a nomenclatory result of altered priorities of residues around the stereocenter upon dehydration). A comparable fragmentation has been observed in the CID (collision-induced dissociation) mass spectrum of atorvastatin, where the base peak observed at $\mathrm{m} / \mathrm{z} 440$ clearly corresponds to a loss of phenyl isocyanate [22].

In contrast, refluxing 2 with concentrated aqueous hydrochloric acid $(37 \%)$ led to the formation of the complex, bridged product 6. Most likely, this decomposition starts again with lactonization of the 3,5-dihydroxyheptanoate side chain, followed by dehydration to give the unsaturated lactone $\mathbf{3}$. This hypothesis was confirmed by refluxing pure lactone 3 with $37 \%$ hydrochloric acid, resulting in clean conversion into $\mathbf{6}$ as well. In the following, this unsaturated lactone (Michael system) most likely performs an acid-mediated intramolecular attack at C-2 of the electron-rich pyrrole ring. In a cascade of subse- quent reactions, the carboxanilide moiety at $\mathrm{C}-3$ is eliminated and the isopropyl residue, originally located at $\mathrm{C}-2$ of the pyrrole, is shifted to $\mathrm{C}-3$, rendering the annulated, tetrasubstituted pyrrole $\mathbf{6}$. The structure of $\mathbf{6}$ was confirmed by X-ray crystal structure analysis. However, most likely cleavage of the carboxanilide moiety (compare formation of $\mathbf{7}$ from atorvastatin with concentrated sulfuric acid) is not the initial step in the cascade of reactions leading from intermediate 3 to product 6 . In a control experiment, we treated compound 7 with $37 \%$ hydrochloric acid under the above mentioned conditions, but only a complex mixture of decomposition products was obtained, with no indication for formation of $\mathbf{6}$. As the intermediate occurrence of a positive charge at C-2 of the pyrrole ring and a $\mathrm{sp}^{3}$ hybridized C-3 are most likely triggering the elimination of phenyl isocyanate from the pyrrole (see postulated mechanism shown in Scheme 2), we propose the formation of an intermediate $\mathbf{C}$, which is formed via initial acid-mediated electrophilic attack of the unsaturated lactone at C-2 of the pyrrole ring. The resulting carbenium ion should be stabilized as shown in Scheme 3 (B $\leftrightarrow$ B'). Subsequent shift of the isopropyl group from C-2 to C-3 then would give carbenium(-iminium) ion $\mathbf{C}$, which can eliminate protonated phenyl isocyanate under formation of bridged pyrrole 6. A comparable shift of the isopropyl group in atorvastatin has previously been observed only under oxidative conditions, giving rise to pyrrolidone-type degradation products [23].

\section{Conclusion}

Atorvastatin calcium trihydrate (1) is known to be an acid-labile drug, and incubation with dilute mineral acids gives the known lactone 2 , which was further dehydrated to unsaturated lactone 3 under more drastic conditions. Treatment with very strong acids gave two hitherto unknown degradation products, whose structures were elucidated by NMR and crystal structure analysis. The bridged tricyclic product $\mathbf{6}$ was formed with concen-

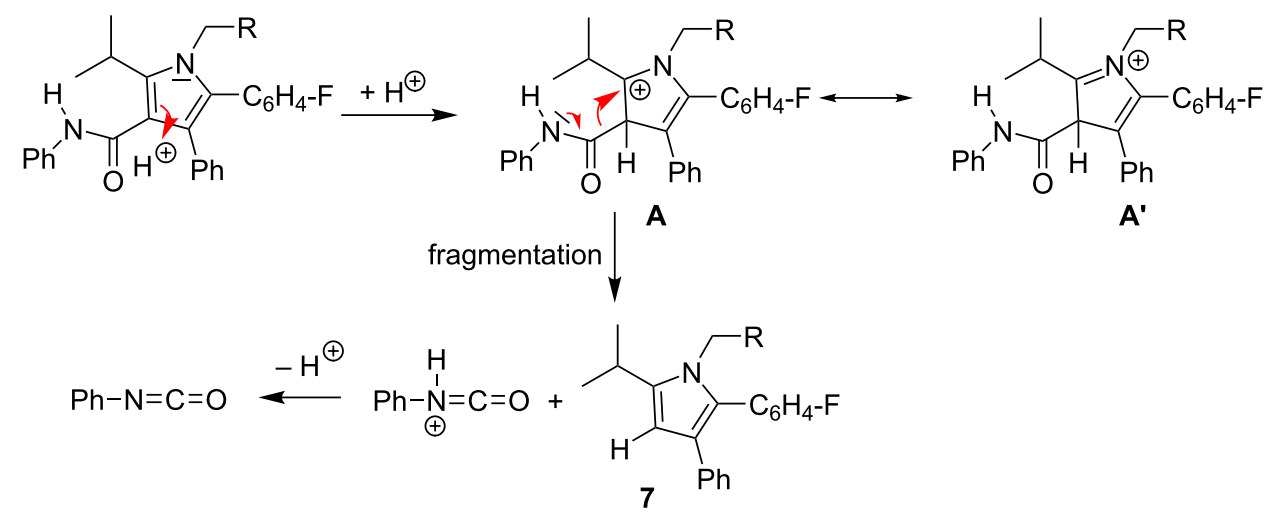




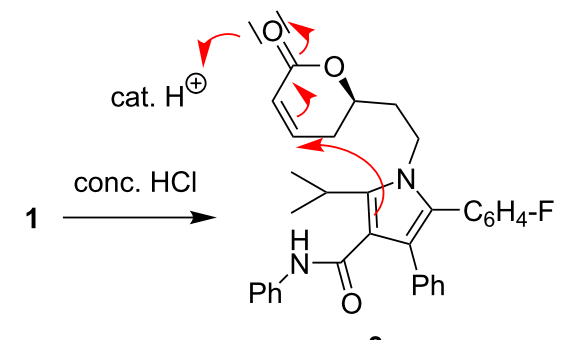

3<smiles>CC(C)c1c(-c2ccccc2)c(CF)n2c1[C@H]1CC(=O)O[C@@H](CC2)C1</smiles>

6

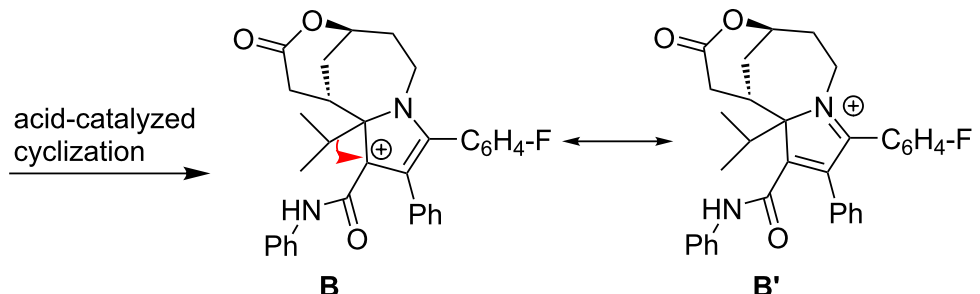

B migration

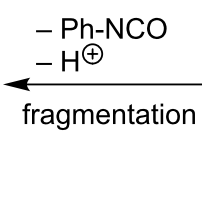<smiles>CC(C)C(C(=O)Nc1ccccc1)C1=C(CCF)N2CCC3CC(CC(=O)O3)[C@H]2C1</smiles>

C

Scheme 3: Proposed mechanism for the formation of bridged product 6 under cyclization, isopropyl migration and carboxanilide fragmentation.

trated hydrochloric acid, whereas lactone 7 resulted from treatment with concentrated sulfuric acid. We propose mechanisms for the formation of the novel artefacts $\mathbf{6}$ and $\mathbf{7}$ here. But it has to be mentioned that these new artefacts, which are formed only under extremely drastic conditions, are not likely to be relevant in terms of drug safety and control of impurities in launched atorvastatin batches.

\section{Supporting Information}

\section{Supporting Information File 1}

Materials and methods; stress tests and analytical data of the products obtained thereby; details of characterization of $\mathbf{6}$ and $\mathbf{7}$ by X-ray data; crystallographic data for $\mathbf{6}$ and $\mathbf{7}$, NMR spectra of artefacts $\mathbf{2}, \mathbf{3}, \mathbf{6}$, and 7 .

[https://www.beilstein-journals.org/bjoc/content/ supplementary/1860-5397-15-206-S1.pdf]

\section{Supporting Information File 2}

checkCIF/PLATON report (Structure factors for artefacts 6 (wq033) and 7 (wv633)).

[https://www.beilstein-journals.org/bjoc/content/ supplementary/1860-5397-15-206-S2.pdf]

\section{Acknowledgements}

The authors thank Prof. Dr. Herbert Mayr for helpful discussions.

\section{ORCID ${ }^{\circledR} \mathrm{iDs}$}

Franz Bracher - https://orcid.org/0000-0003-0009-8629

\section{Preprint}

A non-peer-reviewed version of this article has been previously published as a preprint doi:10.3762/bxiv.2019.31.v1

\section{References}

1. Woo, J.; Wolfgang, S.; Batista, $\mathrm{H}$. Clin. Pharmacol. Ther. (Hoboken, NJ, U. S.) 2008, 83, 494-497. doi:10.1038/sj.clpt.6100493

2. Klick, S.; Muijselaar, P. G.; Waterval, J.; Eichinger, T.; Korn, C.; Gerding, T. K.; Debets, A. J.; Vandingenen, J.; Sänger, C.; van den Beld, C.; Somsen, G.; de Jong, G. Pharm. Technol. 2004, 29 , 48-66.

3. Blessy, M.; Patel, R. D.; Prajapati, P. N.; Agrawal, Y. K. J. Pharm. Anal. 2014, 4, 159-165. doi:10.1016/j.jpha.2013.09.003

4. Haque, T.; Khan, B. V. Clin. Lipidol. 2010, 5, 615-625.

5. Sirén, H. M. M. J. Biomed. Res. Pract. 2017, 1, 100003. http://hdl.handle.net/10138/236735

6. Oliveira, M. A.; Yoshida, M. I.; Belinelo, V. J.; Valotto, R. S. Molecules 2013, 18, 1447-1456. doi:10.3390/molecules18021447

7. Chowdhury, T.; Jakaria, M.; Bhuiyan, D.; Arifujjaman; Mamur, A. J. Sci. Innovation Res. 2014, 3, 598-601.

8. Zaheer, Z.; Farooqui, M.; Mangle, A. A.; Nikalje, A. Afr. J. Pharm. Pharmacol. 2008, 2, 204-210.

9. Chaudhari, B. G.; Patel, N. M.; Shah, P. B. Chem. Pharm. Bull. 2007, 55, 241-246. doi:10.1248/cpb.55.241

10. Chaudhari, B. G.; Patel, N. M.; Shah, P. B.; Patel, L. J.; Patel, V. P. J. AOAC Int. 2007, 90, 1539-1546. 
11. Mohammadi, A.; Rezanour, N.; Ansari Dogaheh, M.;

Ghorbani Bidkorbeh, F.; Hashem, M.; Walker, R. B. J. Chromatogr., B 2007, 846, 215-221. doi:10.1016/j.jchromb.2006.09.007

12. Seshadri, R. K.; Desai, M. M.; Raghavaraju, T. V.; Krishnan, D.; Rao, D. V.; Chakravarthy, I. E. Sci. Pharm. 2010, 78, 821-834. doi:10.3797/scipharm.1004-14

13. Vukkum, P.; Babu, J. M.; Muralikrishna, R. Sci. Pharm. 2013, 81, 93-114. doi:10.3797/scipharm.1208-06

14. Rakibe, U.; Tiwari, R.; Rane, V.; Wakte, P. Acta Chromatogr. 2019, 31 , 33-44. doi:10.1556/1326.2017.00333

15. Shah, R. P.; Kumar, V.; Singh, S. Rapid Commun. Mass Spectrom. 2008, 22, 613-622. doi:10.1002/rcm.3403

16. Darwish, H. W.; Hassan, S. A.; Salem, M. Y.; El-Zeany, B. A. Spectrochim. Acta, Part A 2016, 154, 58-66. doi:10.1016/j.saa.2015.10.007

17. Hassan, S. A.; Elzanfaly, E. S.; El-Zeany, S. B. A.; Salem, M. Y. Acta Pharm. 2016, 66, 479-490. doi:10.1515/acph-2016-0040

18. Sawant, P.; Maier, M. E. Tetrahedron 2010, 66, 9738-9744. doi:10.1016/j.tet.2010.10.028

19. Stach, J.; Havlíček, J.; Plaček, L.; Rádl, S. Collect. Czech. Chem. Commun. 2008, 73, 229-246. doi:10.1135/cccc20080229

20. Kearney, A. S.; Crawford, L. F.; Mehta, S. C.; Radebaugh, G. W. Pharm. Res. 1993, 10, 1461-1465. doi:10.1023/a:1018923325359

21. Tu, Y.-P. Rapid Commun. Mass Spectrom. 2004, 18, 1345-1351. doi:10.1002/rcm.1475

22. Guo, C.; Jiang, K.; Yue, L.; Xia, Z.; Wang, X.; Pan, Y. Org. Biomol. Chem. 2012, 10, 7070-7077. doi:10.1039/c2ob26011e

23. Cermola, F.; DellaGreca, M.; lesce, M. R.; Montanaro, S.; Previtera, L.; Temussi, F. Tetrahedron 2006, 62, 7390-7395. doi:10.1016/j.tet.2006.05.027

\section{License and Terms}

This is an Open Access article under the terms of the Creative Commons Attribution License (http://creativecommons.org/licenses/by/4.0). Please note that the reuse, redistribution and reproduction in particular requires that the authors and source are credited.

The license is subject to the Beilstein Journal of Organic Chemistry terms and conditions:

(https://www.beilstein-journals.org/bjoc)

The definitive version of this article is the electronic one which can be found at: $\underline{\text { doi: } 10.3762 / \text { bjoc. } 15.206}$ 